\title{
Plasma lipoproteins and renal function during simvastatin treatment in diabetic nephropathy
}

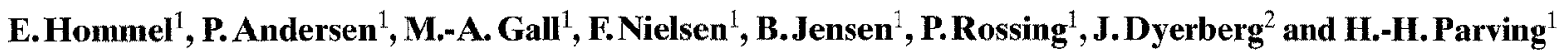 \\ ${ }^{1}$ Steno Memorial and Hvidöre Hospital and ${ }^{2}$ Medical-Laboratory, Copenhagen, Denmark
}

\begin{abstract}
Summary. The aim of this study was to assess the effect of simvastatin on plasma lipoproteins and renal function in hypercholesterolaemic Type 1 (insulin-dependent) diabetic patients with diabetic nephropathy. Twenty-six hypercholesterolaemic (total cholesterol $\geq 5.5 \mathrm{mmol} / \mathrm{l}$ ) Type 1 diabetic patients with nephropathy were enrolled in a double-blind randomized placebo-controlled study for 12 weeks. The active treatment group $(n=14)$ received simvastatin $(10-$ $20 \mathrm{mg} /$ day) for 12 weeks while the remaining 12 patients received treatment with placebo. The results during simvastatin treatment (baseline vs 12 weeks): total cholesterol 6.6 vs $4.8 \mathrm{mmol} / 1(p<0.01)$, LDL-cholesterol 4.25 vs $2.57 \mathrm{mmol} / \mathrm{l} \quad(p<0.01)$ and apolipoprotein B 1.37 vs $1.06 \mathrm{mmol} / \mathrm{l}(p<0.01)$. HDL-cholesterol, and apolipoprotein A-I remained unchanged. Total cholesterol, LDL-choIesterol, HDL-cholesterol, apolipoprotein A-I, apolipoprotein $B$ remained unchanged during placebo treatment. Albuminuria measured during the simvastatin and the place-
\end{abstract}

bo treatment (baseline vs 12 weeks) (the data are logarithmically transformed before analysis because of their positively skewed transformation; geometric mean $(x / \div$ antilog SE) is indicated) was $458(\times / \div 1.58)$ vs $393(\times / \div 1.61)$ and 481 $(x / \div 1.62)$ vs $368(x / \div 1.78 \mu \mathrm{g} / \mathrm{min}(\mathrm{NS})$. Glomerular filtration rate during simvastatin and placebo treatment (baseline vs 12 weeks) was 64 vs 63 and 72 vs $74 \mathrm{ml} \cdot \min ^{-1} \cdot 1.73 \mathrm{~m}^{-2}$, respectively. Two patients receiving simvastatin treatment were withdrawn, one due to gastrointestinal side effects and one due to myalgia. In conclusion, our short-term study in Type 1 diabetic patients with diabetic nephropathy did not reveal any beneficial effect on albuminuria despite a striking lipid-lowering effect of simvastatin in diabetic nephropathy.

Key words: Plasma lipoproteins, albuminuria, diabetic nephropathy, glomerular filtration rate, Type 1 (insulin-dependent) diabetes mellitus.
About $40 \%$ of all Type 1 (insulin-dependent) diabetic patients develop diabetic nephropathy. This complication is characterized by persistent albuminuria ( $>300 \mathrm{mg} / 24 \mathrm{~h}$ ), reduction in glomerular filtration rate and increase in blood pressure [1].

Increased mortality and morbidity in the Type 1 diabetic patients is mainly due to the development of diabetic nephropathy. Borch-Johnsen et al. [2] have shown that the relative cardiovascular mortality in younger Type 1 diabetic patients with nephropathy is 50 200 times higher than in the non-diabetic background population. Hyperlipidaemia is a well-known risk factor for developing cardiovascular diseases. Hyperlipidaemia is more common in Type 1 diabetic patients and especially frequent in diabetic patients with nephropathy compared with the background population [3]. Thus, hyperlipidaemia might be regarded as a consequence of chronic nephropathy. However, other studies suggest that hyperlipidaemia may also contribute to the development and progression of kidney diseases including diabetic nephro- pathy [4-7]. The initial event in the proposed pathogenesis of lipid-induced chronic progressive renal disease is a glomerular basement membrane injury leading to increased permeability and proteinuria [4]. A preliminary uncontrolled study has suggested that lipid lowering therapy with simvastatin (a 3-hydroxy-3-methylglutaryl coenzyme A reductase inhibitor) induced a significant reduction in albuminuria in patients with nephrotic syndrome of different origin [8].

To evaluate the influence of hyperlipidaemia on albuminuria in diabetic nephropathy we performed a 12-week double-blind randomised placebo-controlled study with simvastatin in hypercholesterolaemic Type 1 diabetic patients with nephropathy.

\section{Subjects and methods}

We examined the records of all Type 1 diabetic patients $(n=156)$ with persistent albuminuria greater than $300 \mathrm{mg} / 24 \mathrm{~h}$, who attended the outpatient clinic at Hvidöre hospital during 1990. All Type 1 diabetic patients who fulfilled the following inclusion criteria were 
Table 1. Clinical data in 21 hypercholesterolaemic Type 1 (insulindependent) diabetic patients with nephropathy

\begin{tabular}{|c|c|c|}
\hline & Placebo & Simvastatin \\
\hline Sex (male/female) & $6 / 3$ & $6 / 6$ \\
\hline Age (years) ${ }^{\mathrm{a}}$ & $35(4)$ & $41(9)$ \\
\hline Duration of diabetes (years) ${ }^{a}$ & $27(8)$ & $27(10)$ \\
\hline Retinopathy & & \\
\hline (background/proliferative) & $2 / 7$ & $2 / 9$ \\
\hline Insulin dose $\left(\mathrm{U} \cdot \mathrm{kg}^{-1} \cdot 24 \mathrm{~h}^{-1}\right)^{\mathrm{a}}$ & $0.64(0.1)$ & $0.65(0.18)$ \\
\hline Body mass index $\left(\mathrm{kg} / \mathrm{m}^{2}\right)^{\mathrm{a}}$ & $23.6(3)$ & $24.5(4)$ \\
\hline \multicolumn{3}{|l|}{ Antihypertensive therapy } \\
\hline ACE-inhibitors & 8 & 8 \\
\hline Beta-blockers & 6 & 3 \\
\hline Diuretics & 9 & 11 \\
\hline $\mathrm{Ca}^{++}$channel blockers & 2 & 4 \\
\hline Hydralazine & 1 & 3 \\
\hline
\end{tabular}

${ }^{a}$ Mean (SD); ACE, angiotensin converting enzyme

invited to participate in the study; diabetic nephropathy according to established criteria (i.e. persistent proteinuria, diabetic retinopathy, diabetes of more than 10-years duration, and no clinical or laboratory evidence of kidney or renal tract disease other than diabetic glomerulosclerosis) [9], total cholesterol $\geq 5.5 \mathrm{mmol} / 1$, age 18 50 years and serum creatinine $\leq 200 \mu \mathrm{mol} / \mathrm{l}$. Total cholesterol $\leq 5.5 \mathrm{mmol} / \mathrm{l}(n=62)$, age $(n=10)$, kidney transplantation $[n=7]$ and serum creatinine $\geq 200 \mu \mathrm{mol} / 1(n=10)$ or enrollment in other studies $(n=33)$, excluded 122 patients from the study. Eight eligible patients did not wish to participate in the study. The remaining $26 \mathrm{pa}-$ tients whose clinical data are shown in Table 1, were enrolled in the trial after being given verbal and written information. The study was approved by the local Ethical Committee of the county of Copenhagen.

All patients had been insulin-dependent from the time of diagnosis and were receiving at least two daily injections of insulin. All patients received their usual antihypertensive treatment during the total study period and the dosages were unchanged (Table 1). Apart from the antihypertensive drugs and insulin, none of the patients were taking any other drugs. All the patients who had total cholesterol greater than $5.5 \mathrm{mmol} / \mathrm{l}$ were given dietary advice for a diet of $50 \%$ carbohydrate, $15 \%$ protein and $35 \%$ fat with no sodium restriction. Total cholesterol was remeasured 6 weeks later. All 26 patients still had total cholesterol values over $5.5 \mathrm{mmol} / \mathrm{l}$ and no changes were observed in glycaemic control and in body weight. During the following 3 weeks baseline measurements were performed. Patients were excluded from the study if baseline total cholesterol values dropped below $5 \mathrm{mmol} / \mathrm{l}$. The patients were allocated to either simvastatin treatment $10 \mathrm{mg}$ per day or placebo treatment in a double-blind study. The patients' total cholesterol was evaluated at 6 weeks in order to titrate the dosages of simvastatin or placebo. The dosage of simvastatin was increased to $20 \mathrm{mg}$ (two tablets) or two tablets in the case of placebo if the total cholesterol increased to $5.2 \mathrm{mmol} / \mathrm{l}$ or more.

Venous blood samples were collected after an overnight fast. Total cholesterol was measured enzymatically using CHOD-PAP (cholesterol esterase, cholesterol oxidase and paraminophenazon) reagent from Boehringer Mannheim GmbH (Mannheim, FRG). HDL-cholesterol was measured after precipitation of other lipoproteins with phosphotungstic acid [10]. LDL-cholesterol was calculated using Friedewald's formula [11]. Apolipoprotein A-I and apolipoprotein $B$ were measured by end-point turbidimetry, with commercially available antisera and standards from Hoffmann-La Roche Ltd. (Basel, Switzerland). Lipoprotein (a) (Lp(a)) was determined with reagents from Pharmacia (Uppsala, Sweden). The principle is two-site immunoradiometric assay (2-site IRMA) with two different monoclonal antibodies.

Haemoglobin, differential count, platelets, alkaline phosphatase, aspartate aminotransferase, alanine aminotransferase, creatinine kinase, bilirubin, serum albumin, sodium, potassium and serum creatinine were measured on each patient by conventional laboratory techniques.

Blood glucose was measured hourly during the 4- $\mathrm{h}{ }^{51} \mathrm{Cr}$-EDTA clearance period by a hexokinase method [12]. Haemoglobin $\mathrm{A}_{1 c}$ $\left(\mathrm{HbA}_{1 c}\right.$ ) was determined by Diamat analyser (Bio-Rad, Richmond, Calif., USA) [13]. Normal range of $\mathrm{HbA}_{\mathrm{ic}}$ was $4.1-6.1 \%$ of total $\mathrm{Hb}$.

Renal function was measured at baseline, and at 12 weeks $i . v$. injection of $3.7 \mathrm{MBq}{ }^{51} \mathrm{Cr}$-EDTA (08.30 hours) by studying the disappearance from plasma for $4 \mathrm{~h}$. Venous blood samples were drawn at $180,200,220$ and $240 \mathrm{~min}$ after injection [14]. The patients rested supine during the entire investigation period except while voiding urine; $200 \mathrm{ml}$ of tap water was given per hour during the clearance period. Urinary albumin excretion was measured by radioimmunoassay [15] during the $4-\mathrm{h}{ }^{51} \mathrm{Cr}-\mathrm{EDTA}$ clearance period and in two $24-\mathrm{h}$ urine samples which were collected at baseline and after 12 weeks. The two latter samples were analysed for urea concentration by conventional technique. Protein intake was calculated from the nitrogen content of the urea and an estimated value of non-urea nitrogen of $31 \mathrm{mg} \cdot \mathrm{kg}^{-1} \cdot \mathrm{day}^{-1}$ [16]. Assuming a constant nitrogen balance, nitrogen intake $=$ nitrogen content of urea plus non-urea nitrogen; protein intake $(\mathrm{g} /$ day $)=$ nitrogen intake $\times 6.25$ [17]. Sterility of urine was estimated by quantitative culturing.

Arterial blood pressure was measured by an automated, electronic device (Takeda Medical UA-750, Tokyo, Japan) [18] on the right arm with an appropriately sized cuff $(25 \times 12 \mathrm{~cm})$ after at least 10 -min rest in the supine position. Two readings were taken at the start and the end of the clearance period. Furthermore, two readings were performed when the patients visited the outpatient clinic at 6 weeks at 08.30 hours.

\section{Statistical analysis}

Results are expressed as means and standard deviation (SD). Urinary albumin excretion and $L p(a)$ were logarithmically transformed before analysis because of their positively skewed distribution; the geometric mean $(x / \div$ antilog SE) is indicated. We estimated the changes in urinary albumin excretion, total cholesterol, LDL-cholesterol, apolipoprotein B and glomerular filtration rate. We estimated the relative change in albuminuria by calculating the ratio between the geometric means. Wilcoxon's non-parametric test for paired comparison and analysis of variance in between the groups were performed. A $p$ value less than 0.05 (two-tailed) was considered significant. All calculations were made with a commercially available program (Statgraphic, STSC, Rockville, Md., USA).

\section{Results}

The simvastatin-treated group received an average daily dosage of $10 \mathrm{mg}$ and $12.5 \mathrm{mg}$ after 6 and at 12 weeks, respectively.

Two patients, both receiving simvastatin were withdrawn, one due to gastrointestinal symptoms and one due to myalgia. The plasma creatinine kinase in the patient with myalgia was within normal range (50-270 U/1). Three patients were removed from the study since the baseline total cholesterol values had dropped below $5 \mathrm{mmol} / \mathrm{l}$, all three patients belonged to the placebotreated group.

The plasma concentrations of total cholesterol, LDLcholesterol and apolipoprotein B were significantly reduced in the simvastatin-treated group during the 12 weeks treatment $(p<0.01)$ (Table 2). No changes were observed in the placebo-treated group (Table 2). Significant differences $(p<0.01)$ in mean changes were observed from baseline to 12 weeks between the simvas- 
Table 2. Effect of simvastatin treatment on plasma lipoproteins in hypercholesterolaemic Type 1 (insulin-dependent) diabetic patients with nephropathy

\begin{tabular}{|c|c|c|c|c|c|c|}
\hline \multirow[t]{2}{*}{ Week } & \multicolumn{3}{|l|}{ Placebo } & \multicolumn{3}{|l|}{ Simvastatin } \\
\hline & 0 & 12 & $p$ & 0 & 12 & $p$ \\
\hline $\begin{array}{l}\text { Total-cholesterol } \\
(\mathrm{mmol} / \mathrm{)})\end{array}$ & $6.8 \pm 1$ & $6.8 \pm 1$ & NS & $6.4 \pm 0.9$ & $4.8 \pm 0.7$ & $<0.01$ \\
\hline $\begin{array}{l}\text { LDL-cholesterol } \\
(\mathrm{mmol} / \mathrm{l})\end{array}$ & $4.6 \pm 1$ & $4.7 \pm 1$ & NS & $4.2 \pm 0.8$ & $2.6 \pm 0.5$ & $<0.01$ \\
\hline $\begin{array}{l}\text { VLDL-cholesterol } \\
(\mathrm{mmol} / \mathrm{)})\end{array}$ & $0.84 \pm 0.4$ & $0.77 \pm 0.3$ & NS & $0.61 \pm 0.2$ & $0.67 \pm 0.3$ & NS \\
\hline $\begin{array}{l}\text { HDL-cholesterol } \\
(\mathrm{mmol} / \mathrm{l})\end{array}$ & $1.28 \pm 0.3$ & $1.26 \pm 0.3$ & NS & $1.49 \pm 0.5$ & $1.53 \pm 0.5$ & NS \\
\hline $\begin{array}{l}\text { Triglycerides } \\
(\mathrm{mmol} / \mathrm{l})\end{array}$ & $1.86 \pm 0.8$ & $2.06 \pm 0.8$ & NS & $1.36 \pm 0.4$ & $1.49 \pm 0.6$ & NS \\
\hline $\begin{array}{l}\text { Apolipoprotein A-I } \\
(\mathrm{mmol} / \mathrm{l})\end{array}$ & $1.54 \pm 0.3$ & $1.62 \pm 0.2$ & NS & $1.70 \pm 0.3$ & $1.77 \pm 0.3$ & NS \\
\hline $\begin{array}{l}\text { Apolipoprotein B } \\
(\mathrm{mmol} / \mathrm{)})\end{array}$ & $1.65 \pm 0.4$ & $1.66 \pm 0.4$ & NS & $1.37 \pm 0.2$ & $1.06 \pm 0.2$ & $<0.01$ \\
\hline $\mathrm{Lp}(\mathrm{a})(\mathrm{mg} /)$ & $163(\times / \div 1.68)$ & $165(x / \div 1.70)$ & NS & $181(\times / \div 1.47)$ & $176(x / \div 1.46)$ & NS \\
\hline
\end{tabular}

Values are given as mean $\pm S D ; L P(a)$ is given as geometric mean $(\times 1 \div \operatorname{antilog} S E)$

tatin-treated group and the placebo-treated group (respectively): total cholesterol $(\mathrm{mmol} / \mathrm{l})-1.58 \pm 0.25$ vs $0.078 \pm 0.25 ;$ LDL-cholesterol $(\mathrm{mmol} / \mathrm{l})-1.67 \pm 0.21$ vs $0.013 \pm 0.21$; apolipoprotein $B(\mathrm{~g} / \mathrm{l}) \quad-0.31 \pm 0.67$ vs $0.06 \pm 0.05 . \mathrm{Lp}(\mathrm{a})$ and apolipoprotein A-I were unchanged in both groups (Table 2).

Urinary albumin excretion, glomerular filtration rate, and arterial blood pressure were about the same in the simvastatin-treated group and in the placebo-treated group (Table 3). $\mathrm{HbA}_{1 \mathrm{c}}$ and blood glucose were comparable in both groups after 12 weeks treatment (Table 3).

There was no difference at baseline or at 12 weeks in protein intake calculated from urea excretion between the simvastatin-treated group and the placebo-treated group (baseline vs 12 weeks) simvastatin-treated group $74 \pm 17 \mathrm{~g} /$ day vs $78 \pm 17$ and placebo-treated group $67 \pm 21$ vs $66 \pm 26$ g/day.

Plasma concentrations of alkaline phosphatase, creatinine kinase, aspartate aminotransferase, alanine aminotransferase, bilirubin, albumin, $\mathrm{Hb}$, differential counts, platelets, sodium, potassium, and creatinine were comparable in the two groups.

\section{Discussion}

Our double-blind placebo-controlled study has shown that albuminuria, arterial blood pressure and glomerular filtration rate remain about the same during 12 weeks' treatment with simvastatin in hypercholesterolaemic, Type 1 diabetic patients with nephropathy. A significant reduction in total cholesterol, LDL-cholesterol and apolipoprotein B was induced by simvastatin treatment. The two groups were comparable at baseline evaluation. A confounding influence of arterial blood pressure, antihypertensive treatment, dietary protein intake and metabolic control on albuminuria and glomerular filtration rate can be excluded since these variables remained almost unchanged during the study.

In 1982, Moorhead et al. [4] advocated the concept that chronic progressive kidney disease may be mediated by abnormalities of the lipid metabolism. Numerous studies in different animal models $[6,19,20]$ support this hypothesis. Furthermore, diet-induced hypercholesterolaemia increases glomerular capillary hydraulic pressure and albuminuria and accelerates the course of mesangial expansion and focal glomerulosclerosis in rats with normal or reduced renal mass or in rats suffering from chronic aminonucleoside nephrosis [6,21]. Conversely, lowering the levels of plasma lipids with lovastatin or clofibric acid reduces the transglomerular capillary hydraulic pressure difference, albuminuria and the rate of progression of renal disease in the above-mentioned animal models [20, $22]$. The beneficial effect on albuminuria $(50-90 \%$ decrease) could be demonstrated after treatment for 4 weeks with no further improvement shown by prolonging the treatment period [20].

A link between glomerular hypertension and albuminuria and the development and progression of diabetic glomerulopathy has been suggested by Hostetter et al. [23] and strongly supported by numerous investigations as reviewed by Parving et al. [24].

The presence of normal glomerular hydraulic pressure has been suggested as a likely explanation for the protection against development of albuminuria and focal glomerularsclerosis in the hyperlipidaemic analbuminaemic rat [25]. In contrast to the extensive information on lipid nephrotoxicity in experimental animals, data in human renal disease is scanty. Rabelink et al. [8] reported in a uncontrolled study that simvastatin (40 mg/day) substantially reduces hyperlipidaemia and albuminuria with no changes in serum creatinine in seven patients suffering from nephrotic syndrome due to different nondiabetic glomerulopathies. The reduction in albuminuria was present in five of seven and six of seven of these pa- 
Table 3. Effect of simvastatin treatment on albuminuria, glomerular filtration rate, arterial blood pressure, $\mathrm{Hb} \mathrm{A}_{\mathrm{ic}}$ and blood glucose concentration in hypercholesterolaemic Type 1 (insulin-dependent) diabetic patients with nephropathy

\begin{tabular}{|c|c|c|c|c|c|c|}
\hline \multirow[t]{2}{*}{ Week } & \multicolumn{3}{|l|}{ Placebo } & \multicolumn{3}{|l|}{ Simvastatin } \\
\hline & 0 & 12 & $p$ & 0 & 12 & $p$ \\
\hline $\begin{array}{l}\text { Albuminuria } \\
(\mu \mathrm{g} / \mathrm{min})\end{array}$ & $481(\times / \div 1.62)$ & $368(\times / \div 1.78)$ & NS & $458(\times / \div 1.58)$ & $393(\times / \div 1.61)$ & NS \\
\hline $\begin{array}{l}\text { Albuminuria } \\
(\mathrm{mg} / 24 \mathrm{~h})\end{array}$ & $755(\times / \div 1.72)$ & $610(x / \div 1.66)$ & NS & $698(x / \div 1.68)$ & $531(x / \div 1.60)$ & NS \\
\hline $\begin{array}{l}\text { Glomerular filtration } \\
\text { rate }\left(\mathrm{ml} \cdot \mathrm{min}^{-1} \cdot 1.73 \mathrm{~m}^{2-1}\right)\end{array}$ & $72 \pm 23$ & $74 \pm 23$ & NS & $64(30)$ & $63(29)$ & NS \\
\hline $\begin{array}{l}\text { Arterial Blood } \\
\text { pressure }(\mathrm{mm} \mathrm{Hg})\end{array}$ & $135 / 83 \pm 19 / 11$ & $138 / 86 \pm 18 / 11$ & NS & $140 / 84 \pm 18 / 11$ & $135 / 82 \pm 21 / 10$ & NS \\
\hline $\mathrm{Hb}_{\mathrm{ic}}(\%)$ & $9.3 \pm 1$ & $9.6 \pm 1$ & NS & $9.3(1)$ & $9.7 \pm 2$ & NS \\
\hline Blood glucose $(\mathrm{mmol} / \mathrm{l})$ & $11 \pm 4$ & $12 \pm 4$ & NS & $14 \pm 5$ & $11 \pm 4$ & NS \\
\hline
\end{tabular}

Values are given as mean (SD); Albuminuria is given as geometric mean $(x / \div \operatorname{antilog} \mathrm{SE})$; ${ }^{\text {a }}$ Albuminuria measured during the renal clearance procedure

tients after 6 and 48 weeks of treatment, respectively. Sasaki et al. [26] also applied an uncontrolled design to evaluate the effect of pravastatin on proteinuria in seven hypercholesterolaemic Type 2 diabetic patients with micro- and macroalbuminuria. Proteinuria was significantly reduced in all seven patients (average $60 \%$ ) after treatment for 4 weeks, and no further reduction in proteinuria was observed after 12 weeks of pravastatin treatment. In contrast, Deslypere et al. [27] observed proteinuria (mean $0.5 \mathrm{~g} / \mathrm{l}$ ) on one or more occasions in 10 out of $120(8 \%)$ hypercholesterolaemic patients treated with simvastatin. The proteinuric patients were treated with $40 \mathrm{mg} /$ day. Four patients had persistent albuminuria (mean $0.25 \mathrm{~g} / \mathrm{l}$ ) and six patients had only intermittent albuminuria. Our short-term study (12 weeks) did not reveal any beneficial effect on albuminuria despite a striking lipid-lowering effect of simvastatin in diabetic nephropathy. The above-mentioned studies do not suggest that the lack of effect on albuminuria is due to the length of our treatment period. Furthermore, albuminuria can be reduced in incipient and overt diabetic nephropathy by treatment lasting only a few days or weeks e.g. antihypertensive drugs, low protein diet and nonsteroidal anti-inflammatory drugs [28-32]. Our study underscores the necessity of having a matched untreated parallel control group, since we found a spontaneous reduction in albuminuria of 17-19\%. Recently, Mulec et al. [5] have reported a significant correlation between serum cholesterol concentration and the rate of decline in glomerular filtration rate in Type 1 diabetic patients suffering from diabetic nephropathy. The preliminary result from this ongoing observational study suggests that it might be worth while to conduct a long-term (several years) randomised treatment trial in hyperlipidaemic patients with diabetic nephropathy using rates of progression of renal function and structure lesions as end-points.

We found that total cholesterol, LDL-cholesterol and apolipoprotein B significantly reduced during 12 weeks treatment with simvastatin in hypercholesterolaemic Type 1 diabetic patients with nephropathy. The findings are in accordance with studies performed in hyperlipidaemic patients with nephrotic syndrome [8] and in
Type 2 (non-insulin-dependent) diabetic patients [33] where simvastatin reduced total cholesterol with 36-37\% and decreased LDL-cholesterol with $28-39 \%$. The decrease in total cholesterol and LDL-cholesterol during simvastatin treatment is due to inhibition of 3-hydroxy-3methylglutaryl-coenzyme A reductase (HMG-CoA reductase), the rate-controlling enzyme in cholesterol synthesis and due to increase in the synthesis of hepatic LDL-receptors. HDL-cholesterol has previously been reported to either increase during lovastatin treatment in hypercholesterolaemic patients, or be unchanged in hypercholesterolaemia in Type 2 diabetic patients [33], but we did not observe any change in HDL-cholesterol or in apolipoprotein A-I.

In conclusion, the possible importance of hyperlipidaemia in the initiation and progression of human renal disease still remains to be established. The major end-point for further long-term prospective studies of lipid-lowering treatment in glomerulopathies should be glomerular filtration rate, determined by an isotope or inulin method, and quantitative evaluation of structural lesions.

Acknowledgements. Simvastatin and placebo tablets were supplied by Merck Sharpe and Dohme.

\section{References}

1. Parving $\mathrm{H}-\mathrm{H}$, Smidt U, Friisberg B, Bonnevie-Nielsen V, Andersen AR (1981) A prospective study of glomerular filtration rate and arterial blood pressure in insulin-dependent diabetics with diabetic nephropathy. Diabetologia 20:457-461

2. Borch-Johnsen K, Andersen PK, Deckert T (1985) The effect of proteinuria on relative mortality in Type 1 (insulin-dependent) diabetes mellitus. Diabetologia 28: 590-596

3. Kostner GM, Karadi I (1988) Lipoprotein alterations in diabetes mellitus. Diabetologia 31: 717-722

4. Moorhead JF, El-Nahas M, Chan MK, Varghese Z (1982) Lipid nephrotoxicity in chronic progressive glomerular and tubulo-interstitial disease. Lancet II: 1310-1311

5. Mulec H, Johnson S-AA, Björck S (1990) Relation between serum cholesterol and diabetic nephropathy. Lancet 335: 15371538 
6. Diamond JR, Karnovsky MJ (1987) Exacerbation of chronic aminonucleoside nephrosis by dietary cholesterol supplementation. Kidney Int 32: 671-677

7. Kasiske BI, O’Donnell M, Clearly MP, Keane WF (1989) Effects of reduced renal mass on tissue lipids and renal injury in hyperlipidemic rats. Kidney Int 35: 40-47

8. Rabelink AJ, Hene RJ, Erkelens DW, Joles JA, Koomans HA (1990) Partial remission of nephrotic syndrome in patients on long-term simvastatin. Lancet 335: 1045-1046

9. Parving H-H, Andersen AR, Smidt UM, Svendsen PA (1983) Early aggressive antihypertensive treatment reduces the rate of decline in diabetic nephropathy. Lancet I: 1175-1179

10. Kattermann R, Joworek D, Möller G (1984) Multicenter study of a new enzymatic method of cholesterol determination. J Clin Chem Clin Biochem 22: 245-251

11. Friedewald WT, Levy RI, Frederikson DS (1972) Estimation of the concentration of low density lipoprotein cholesterol in plasma without use of the preparative ultracentrifuge. Clin Chem 18: $499-502$

12. Andersen I, Hannibal S (1983) Analytical and economical optimization of a glucose method with immobilized enzymes. I Automatic Chemistry 4: 188-192

13. Goldstein DE, Peth SB, England JD, Randall LH, DaCosta J (1980) Effects of acute changes in blood glucose on $\mathrm{HbA}_{1 \mathrm{c}}$. Diabetes 29:623-628

14. Bröchner-Mortensen J (1972) A simple method for the determination of glomerular filtration rate. Scand J Clin Lab Invest 30 : $271-274$

15. Miles DW, Mogensen CE, Gundersen HJG (1970) Radioimmunoassay for urinary albumin using a single antibody. Scand J Clin Lab Invest 26: 5-11

16. Maroni BJ, Steinman TI, Mitch WE (1985) A method for estimating nitrogen intake of patients with chronic renal failure. Kidney Int 27:58-65

17. Isaksson B (1980) Urinary nitrogen output as a validity test in dietary surveys. Am J Clin Nutr 33: 4-5

18. Carlsen J, Køber L, Hansen A-D, Sindling A, Andersen P (1988) Electronic measurement of blood pressure. Technical and clinical assessment of medical UA 751. Ugeskr Laeger 150: 12801282

19. Kasiske Bl, O'Donnell MP, Keane WF (1987) The obese Zucker rat model of glomerular injury in Type 1 (insulin-dependent) diabetes. J Diab Compl 1: 26-29

20. Kasiske BL, O'Donnell MP, Garvis WJ, Keane WF (1988) Pharmacologic treatment of hyperlipidemia reduces glomerular injury in rat 5/6 nephrectomy model of chronic renal failure. Circ Res 62: 367-374

21. Kasiske BL, O'Donnell MP, Schmitz PG et al. (1990) Renal injury of diet-induced hypercholesterolemia in rats. Kidney Int 37: 880-891
22. Kasiske BL, O'Donnell MP, Clearly MP, Keane WF (1988) Treatment of hyperlipidemia reduces glomerular injury in obese Zucker rats. Kidney Int 33: 667-672

23. Hostetter TT, Rennke HG, Brenner BM (1982) The case for intrarenal hypertension in the initiation and progression of diabetic and other glomerulopathies. Am J Med 72: 375-380

24. Parving H-H, Viberti GC, Keen $\mathrm{H}$, Christiansen JS, Lassen NA (1983) Hemodynamic factors in the genesis of diabetic microangiopathy. Metabolism 32:943-949

25. Zatz R, Prado EBA, Prado MJBA (1989) Aging analbuminemic rats fail to develop focal glomerular sclerosis. Kidney Int 35: 442

26. Sasaki T, Kuratya H, Nomura K, Utsunomiya K, Ikeda Y (1990) Amelioration of proteinuria with Pravastatin in hypercholesterolemic patients with diabetes mellitus. Jpn J Med 29: 156-163

27. Deslypere JP, Delanghe J, Vermeulen A (1990) Proteinuria as complication of simvastatin treatment. Lancet 336: 1045-1046

28. Parving H-H, Kastrup J, Smidt UM, Andersen AR, Feldt-Rasmussen B, Sandahl Christiansen J (1984) Impaired autoregulation of glomerular filtration rate in Type 1 (insulin-dependent) diabetic patients with nephropathy. Diabetologia 27: 547-542

29. Hommel E, Mathiesen E, Edsberg B, Bahnsen M, Parving H-H (1986) Acute reduction of arterial blood pressure reduces urinary albumin excretion in Type 1 (insulin-dependent) diabetic patients with incipient nephropathy. Diabetologia 29:211-215

30. Wiseman MI, Bognetti ZE, Dodds R, Keen H, Viberti GC (1987) Changes in renal function in response to protein restricted diet in Type 1 (insulin-dependent) diabetic patients. Diabetologia 30 : $154-159$

31. Hommel E, Mathiesen E, Arnold-Larsen S, Edsberg B, Olsen UB, Parving H-H (1987) Effects of indomethacin on kidney function in Type 1 (insulin-dependent) diabetic patients with nephropathy. Diabetologia 30:78-81

32. Mathiesen ER, Hommel E, Olsen UB, Parving H-H (1988) Elevated urinary prostaglandin excretion and the effect of indomethacin on renal function in incipient nephropathy. Diab Med 5: $145-149$

33. Garg A, Grundy SM (1988) Lovastatin for lowering cholesterol levels in non-insulin-dependent diabetes mellitus. N Engl J Med 318: $81-86$

Received: 29 August 1991

and in revised form: 23 December 1991

Dr. E.Hommel

Steno Memorial and Hvidöre Hospital

Niels Steensens Vej 2

DK-2820 Gentofte

Denmark 